indicate that the red color is due to two microorganisms, which probably originated in the sea salt used in curing the fish. The color varies from pale pink to deep crimson, the former the result of the growth of a spirochete, and the latter produced by a bacillus form.

These microorganisms grow in completely saturated brine on salt fish and on salt piles, but no growth appears in media containing less than 15 per cent. of salt by weight. The most favorable temperature for the growth of both organisms is between $50^{\circ}$ and $60^{\circ} \mathrm{C}$. indicating that the salt lagoons of the tropies are probably sources of infection. Sunlight is not germicidal, which also points to their tropical origin where pigmentation is required against bright sunlight. Ordinary bacteria are killed by ten minutes exposure to the bright sunshine. Salt acts as a preservative preventing the growth of most organisms, but here is an instance of just the opposite effect.

In summary, the results of recent investigation indicate that the cause of the red color in solar salt and brine is due to organisms as indicated above and that their source is salt produced by solar evaporation. Both European and American sea salt is infected, but mined salt is free from their presence.

The studies made by the Bureau of Fisheries and by others before it (See Bibliography published by Bureau of Fisheries) have suggested to the writer that possibly causes allied to those now producing red coloration in solar salts may have been active as long ago as the Permian. Whatever may be the main cause of the reddening of the Permian potash salts, the question naturally arises, is the reddening in the potash salts of the German Permian, the Alsatian Oligocene and the Spanish Tertiary deposits due to the same or similar agencies that are causing reddening in the solar salt of the present time. It is probable that both types of salts have been formed under essentially similar conditions, that is, salt pan conditions. If this last statement be admitted, then it points to the growth of bacteria, at least intermittently, from the Permian down to the present.

This is presented to induce further study along this line and to elicit discussion and opinions. Such studies may also throw some light on temperatures during Permian and later geologic time.

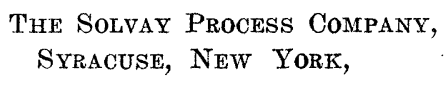

\section{POPULAR SCIENCE}

To the Editor of ScIENCE: I am sorry to see that Dr. E. Dorsey confirms ${ }^{1}$ the opinion expressed by Dr. Brooks ${ }^{2}$ and myself ${ }^{3}$ that science is relatively losing ground in popular interest and esteem. I fear he is right also in saying that this is in part the fault of scientists. For the prevalent indifference and even hostility of the public to the higher teachings of science may be matched by the indifference and even hostility of certain scientific men to the "vulgarisation of science."

It is quite true, as Dr. Dorsey points out, that isolated facts, however numerous and authentic, do not constitute science. I have kept that point in mind in all our Science Service work. For instance I said in a recent magazine article: ${ }^{4}$

We can get from the reading of science not only new things to think about, but, what is more important, new ways of thinking about things.

But I hope that Dr. Dorsey will not discourage those of us who are trying to get a larger amount of "mere information" in the newspapers. A few more facts are really needed to season the mass of fiction there. We may also hope to get over some idea of the relations between facts and how the scientist finds his facts and what he gets out of them. But we can not expect that the newspaper reader will aequire the habit of persistent experimentation, constant criticism, rigorous reasoning, projection of hypotheses, balancing of theories and suspension of judgment characteristic of the scientifie mind. If the layman

1 SCIENCE, 55: 374, 1922.

2 Journal Washington Academy of Sciences, 12: $73,1922$.

3 SCIENCE, 55: 241, 1922.

4 "Science from the Side Lines," in The Century, January, 1922. 
could get all this he would be not a layman but a scientist. The most we can expect is that the layman may gain sufficient acquaintance with scientific thinking to understand the methods and aims of research and to appreciate its value to civilization. That he does not commonly acquire such comprehension and appreciation is because the men who understand the value of science have been too often unwilling to take the pains to impart their information and inspiration to him.

We are told that Agassiz required of his students in every department to prepare "first a monograph, second a scientific lecture, third a popular lecture, fourth a simple child's tale." How many of our annual army of Ph.D.'s would pass the third and fourth of these intelligence tests? Agassiz had his reward in the dozens of devoted disciples who became the teachers of the next generation and in the thousands of young people who bear his badge as they search forest and strand with curious eyes. But we need more men of the Agassiz type-and we seem to be getting fewer.

England, as I showed in ScIence, seems to have more men of high standing who are willing and able to translate their learning into the vernacular. It would be hard to match in all America the popular lecturers of the Royal Institution from Faraday to Bragg. But even in England we hear complaints of the growing gulf between the specialist and the public. The once-popular lectures to workingmen are now said to be running short of both speakers and hearers. Last year the columns of Nature were filled for months with discussions of why the lay membership of the British Association for the Advancement of Science was falling off. The British Association has always had the advantage of ours in the large number of citizens, not professionallyt engaged in scientific pursuits, who would support and attend the annual meetings but now it is becoming, like the American Association, a congeries of highly specialized sections.

Several of the correspondents in Nature expressed the opinion that the public had lost interest and confidence in science because scientists have lost their fighting spirit and the courage of their convictions. They take everything lying down nowadays and do not dare to defend their views or even defend their right to hold and teach their views.

This is a point worthy of consideration by those American men of science who have adopted the policy of treating with dignified contempt the present legislative and ecclesiastical attacks upon their intellectual freedom. Little is being done in scientific circles to check the rising tide of superstition and intolerance now sweeping over. the land. Perhaps when appropriations are cut off, as in South Carolina, on the ground that the university has an evolutionist on the premises our scientific pacifists may sharpen up their pens and turn out literature as interesting to the general reader as Huxley's debate with Gladstone about the demons who converted the pigs of Gadara into pickled pork.

Dr. Dorsey is wise in putting "accounts of discoveries" first in his list of popular science subjects. But who will write them? I have been hunting in vain for writers who could sense the dramatic elements in such a scene as Archimedes' bath and tell how this ancient graft case led to the law of specific gravity. Who will describe the feelings of Faraday when he saw the loose end of a little magnet rotating about an electrie wire in the dingy laboratory of the Royal Institution and then explain what that had to do with the trolley cars that are passing in the street?

The history of science is as rich a field for the cultivation of good literature as the history of literature, art and music but it remains untilled for want of attention. Students have been trained to look another way. The aim is now to eliminate the personal element from science and reduce it to an abstract and timeless formula. This may be necessary as a scientific method but it naturally results in the decline of interest. The old textbooks are more readable than the modern. A distinguished physicist, in discussing this point with me, said: "When I was in college I had to study Hastings and Beach but I read Deschanel for my own amusement." I am not advising that our textbooks should return to the leisurely literary style of long ago but we can not expect depersonalized science to be popular. Whatever is without "human interest" is not interesting to humanity. Dehydrated potatoes 
are convenient for conveyance but they have to be soaked up before they are palatable.

\section{Science Service}

EDwin E. SLOSSON

WASHINGTON

\section{SCIENTIFIC BOOKS}

An Introduction to Cytology. By Lester W. Sharp. MeGraw-Hill Book Company, New York, 1921. 452 pages, 159 illustrations.

For a subject of such wide interest and great significance as cytology, there are surprisingly few text books. For years Wilson's classic work, "The Cell in Development and Inheritance," has been the chief reference volume, especially of the beginning investigator. Very recently two English texts, one by W. E. Agar, "Cytology, with Special Reference to the Metazoan Nucleus," and another by L. Doneaster, "An Introduction to the Study of Cytology," have appeared. These are good books, dealing in both cases, however, with a rather limited field and largely with animal material. There has long been felt the need for an introductory text which would present an outline of the subject in both its botanical and zoological aspects. The rapid advances made by numerous investigators, working upon a great variety of materials, and the intimate relation of these in many cases to equally rapid developments in the other new science of genetics, have made the writing of a cytological text book a very difficult matter.

Professor Sharp, despite these obstacles, has done an excellent piece of work for he not only covers the fields of botany and zoology, but embraces in his consideration of subjects most of those necessary for an understanding of the scope of cytological knowledge. Very properly, however, he places emphasis upon the topics of greatest general interest. We find, therefore, that of the 452 pages of text, 240 are devoted to the hereditary mechanism and the results of its operation. Zoologists, particularly, will welcome so comprehensive a summary of the achievements of their botanical fellows as Professor Sharp presents. While this is naturally the strong part of the work, zoological material is well considered. Indeed, the author deserves special commendation for the completeness and fairness with which the contributions of zoolo- gists are treated. In view of the general excellence of the book in this respect, it might be permitted, in the interest of the accuracy for which the author very evidently strives, to point out that in a few cases he has allowed his personal studies to influence his presentation of topics concerning which there are differences of opinion. Perhaps the most conspicuous example of this is in the discussion of the differential structure of the chromatin thread. While there may be uncertainty on this point in plant material, there is none in many animal forms.

The method by which the material is presented is entirely to be commended. In recognition of the developmental stage of the subject, Professor Sharp has endeavored to set forth its status by showing what the problems are and how they are being met, rather than by attempting to define in categorical terms the content of our knowledge. The spirit and motives of an investigation are as important as its achievement, and, since cytology is now so largely a matter of discovery, it would be a misrepresentation to exhibit it otherwise than as an active field of research.

As practical measures for such a presentation it may be noted that the numerous illustrations are, almost always, copies of those found in research papers instead of those from text books; extensive bibliographies follow each chapter, offering the means for a comprehension of the extent of the work done and for following up any particular subject ; $^{1}$ there is a full index in which may be found the taxonomic position of all materials discussed; scattered through the chapters are brief historical or critical reviews of nomenclature; there are frequent diagrammatic figures which

1 As indicating the scope and eharacter of these references it may be noted that at the end of Chapter XI, "'The Reduction of the Chromosomes," a total of 170 individuals, of 11 nationalities, are quoted. The distribution of these biologists is interesting, indicating, as it does in a general way, the interest in eytology exhibited in different countries. Of the 170 individuals referred to, there are 54 Americans, 46 Germans, 26 British, 13 French, 9 Japanese, 7 Scandinavians, 6 Belgians, 4 Hollanders, 2 Russians, 2 Italians, and 1 Pole. 